\title{
ENSINAR E APRENDER NAS REDES SOCIAIS DIGITAIS: O CASO DA MATHGURL NO YOUTUBE
}

\section{TEACHING AND LEARNING IN DIGITAL SOCIAL NETWORKS: THE MATHGURL CASE ON YOUTUBE}

José António Moreira1: Universidade Aberta. Portugal. jmoreira@uab.pt

D Ramila Lima Santana e Santana: Instituto Federal de Educação, Ciência e Tecnologia Baiano. Brasil. camilalimasantana@gmail.com

Aitor González Bengoechea*: Universidad Complutense de Madrid. España. aitogonz@ucm.es

*Este artigo foi apoiado pela bolsa de estudos FPU15 / 07114 do Ministério da Ciência, Inovação e Universidades (Espanha).

\section{RESUMO}

Os avanços da Internet, e em particular das redes sociais digitais, têm estimulado de forma decisiva a aprendizagem, para além das estruturas educativas formais. Com a Web 2.0 e com o crescimento das redes sociais como o Facebook, o Twitter ou o YouTube, a ênfase tem sido colocada na aprendizagem em rede e nas potencialidades do designado software social para acesso à informação e ao conhecimento, bem como na capacidade para trabalhar e aprender com os outros numa colaboração global criativa fora das estruturas educacionais convencionais marcada pelo desejo de ligar os mundos da aprendizagem formal e informal. Neste contexto de networking social o número de youtubers tem crescido de uma forma vertiginosa, sendo que alguns destes têm criado canais e vídeos com finalidades educativas. Recorrendo a uma metodologia de cariz qualitativo este estudo procura, pois, analisar um desses canais, centrando-se no caso da youtuber conhecida como Mathgurl, uma jovem portuguesa cujo canal dedicado a ensinar matemática de forma lúdica tem mais de três milhões de visualizações e é uma referência neste campo. As principais conclusões deste estudo remetem-nos para a ideia de que estes espaços não formais de aprendizagem não devem ser encarados como substitutos dos espaços formais de aprendizagem, pelo contrário, devem funcionar como

\footnotetext{
1José António Moreira: Doutor em Ciências da Educação pela Universidade de Coimbra. Professor na Universidade Aberta, Portugal. Coordenador do Núcleo de Estudos de Pedagogia no Ensino Superior no Centro de Estudos Interdisciplinares do Século 20 da Universidade de Coimbra. imoreira@uab.pt
} 
Moreira, J. A.; Lima Santana e Santana, C. \& González Bengoechea, A. Ensinar e aprender nas redes sociais digitais: o caso da MathGurl no YouTube

espaços complementares com características próprias, online, abertos e em rede, e como "gatilhos" motivacionais e mobilizadores dos sujeitos para a aprendizagem da Matemática.

PALAVRAS CHAVE: redes sociais digitais - YouTube - ensino - aprendizagem vídeos.

\section{ABSTRACT}

The development of the Internet, and in particular of digital social networks, have decisively stimulated learning beyond traditional educational structures. With Web 2.0 and the growth of social networks such as Facebook, Twitter or YouTube, network learning and the potential of these networks as a source of access to information and knowledge have been emphasized, as well as the ability to work and learn with other people in a creative global collaboration outside the conventional educational structures and marked by the will to connect the worlds of formal and informal learning. In this context of social networks, the number of youtubers has grown vertiginously, creating, some of them, channels and videos with educational purposes. Using a qualitative methodology, this paper seeks to analyze one of these channels, focusing on the case of the youtuber known as Mathgurl, a young Portuguese woman whose channel dedicated to teaching maths in a playful way has more than three million views and is a reference in this field. The main conclusions of this study lead us to the idea that these non-formal learning spaces should not be considered as substitutes for formal learning spaces, but they should function as complementary spaces with their own characteristics, online, open and in network, and as "triggers" motivators and mobilizers to users for learning maths.

KEY WORDS: digital social networks - YouTube - teaching learning - videos.

\section{ENSEÑANZA Y APRENDIZAJE EN REDES SOCIALES DIGITALES: EL CASO MATHGURL EN YOUTUBE}

\section{RESUMEN}

Los avances de Internet, y en particular de las redes sociales digitales, han estimulado decisivamente el aprendizaje más allá de las estructuras educativas tradicionales. Con la Web 2.0 y el crecimiento de redes sociales como Facebook, Twitter o YouTube, se ha enfatizado el aprendizaje en red y el potencial de estas redes como fuente de acceso a la información y al conocimiento, así como la capacidad para trabajar y aprender con otras personas en una colaboración global creativa fuera de las estructuras educativas convencionales y marcadas por el deseo de conectar los mundos del aprendizaje formal e informal. En este contexto de las redes sociales, el número de youtubers ha crecido vertiginosamente, creando, algunos de ellos, canales y vídeos con finalidades educativas. Utilizando una metodología cualitativa, este estudio busca analizar uno de estos canales, centrándose en el caso de la youtuber conocida como Mathgurl, una joven portuguesa cuyo canal dedicado a la enseñanza de las matemáticas de una manera 
Moreira, J. A.; Lima Santana e Santana, C. \& González Bengoechea, A. Ensinar e aprender nas redes sociais digitais: o caso da MathGurl no YouTube

lúdica tiene más de tres millones de visualizaciones y es una referencia en este campo. Las principales conclusiones de este estudio nos llevan a la idea de que estos espacios de aprendizaje no formales no deben ser considerados como sustitutos de los espacios formales de aprendizaje, sino que deben funcionar como espacios complementarios con sus propias características, en línea, abiertos y en red, y como "gatillos" motivadores y movilizadores de los usuarios para el aprendizaje de las matemáticas.

PALABRAS CLAVE: redes sociales digitales - YouTube - enseñanza aprendizaje videos.

\section{Cómo citar el artículo:}

Moreira, J. A.; Lima Santana e Santana, C. \& González Bengoechea, A. (2019). Ensinar e aprender nas redes sociais digitais: o caso da MathGurl no YouTube. [Teaching and learning in digital social networks: the MathGurl case on YouTube]. Revista de Comunicación de la SEECI, (50), 107-127. doi:

http://doi.org/10.15198/seeci.2019.50.107-127

Recuperado de http://www.seeci.net/revista/index.php/seeci/article/view/622

\section{INTRODUÇÃO}

Nos próximos 50 anos, vamos testemunhar uma explosão de acesso, produção e distribuição de vídeos por comunidades que antes não podiam produzi-los em suas casas, escolas e escritórios. Assim como os computadores e programas gráficos deram aos consumidores o poder da imprensa em suas mesas (mas foi necessária a Internet para tornar todo mundo um editor desde então, já que faltava um canal de distribuição), e como os samplers de áudio digital deram origem a géneros e produtores de música totalmente novos, a tecnologia de vídeo computacional permitirá que esses indivíduos e novas comunidades façam vídeos como parte de sua comunicação diária² (Davis, 1997, p. 46).

Apesar de não se poder prever o que aconteceria com as indústrias da comunicação e entretenimento quando um sujeito comum pudesse controlar os meios de produção e distribuição de comunicação e cultura, muito antes da criação das plataformas de conteúdo audiovisual na internet, estudiosos já sinalizavam que, com o desenvolvimento da tecnologia digital, qualquer pessoa com acesso e conhecimento de utilização dos instrumentos técnicos poderia produzir, caseira e amadoramente, conteúdo audiovisual digital. Embora a literatura sobre as redes sociais digitais sinalizem que o desenvolvimento das tecnologias digitais no contexto da web 2.0 possibilitou o surgimento e crescimento das culturas participativas, entendemos, como Jenkins (2009), que o contrário também é uma verdade.

Se o YouTube parece ter aparecido da noite para o dia, é porque já havia uma miríade de grupos esperando por algo como o YouTube; eles já tinham suas comunidades de prática que incentivavam a produção de mídia DIY, já haviam

\footnotetext{
2 Tradução dos autores.
} 
Moreira, J. A.; Lima Santana e Santana, C. \& González Bengoechea, A. Ensinar e aprender nas redes sociais digitais: o caso da MathGurl no YouTube

criado seus gêneros de vídeos construído redes sociais por meio das quais tais vídeos podiam trafegar. O YouTube pode representar o epicentro da cultura participativa atual, mas não representa o ponto de origem para qualquer das práticas culturais associadas a ele (Jenkins, 2009, p. 145).

Isso implica o entendimento de que as tecnologias digitais, a web 2.0 e mesmo as redes sociais digitais potencializaram práticas, desejos e comportamentos humanos que já existiam e/ou eram idealizados, prospectados. Esses comportamentos, potencializados pelas tecnologias digitais, como a web 2.0 e as redes sociais digitais, ressignificam práticas sociais como entretenimento, busca por informação e aprendizagem. Como resultado, dois novos tipos de utilizadores, prosumers e nativos digitais surgiram. O primeiro é uma evolução do consumidor receptor e passivo, capaz de romper com o esquema de comunicação tradicional e de se tornar tanto um produtor quanto um consumidor de conteúdo, graças às capacidades das tecnologias digitais da informação e comunicação. O segundo, o nativo digital, é um utilizador que concebe a internet e a tecnologia como um modo de vida e que não entende as atividades do seu dia a dia, como se divertir, aprender ou ser informado fora de sua conexão com a rede.

Esses sujeitos, portanto, que têm a internet como um lugar de vivência e produção de conteúdos, saberes e conhecimento, apropriam-se dos ciberespaços de maneira singular, modificando e criando novas formas de interação, comunicação, difusão e construção na dimensão social da comunicação e educação, áreas do conhecimento que importam neste estudo.

No âmbito da comunicação, analisar e compreender o contexto das redes sociais digitais, seu potencial de alcance, sua dinâmica de crescimento e popularização e o impacto destes novos espaços na circulação de informação, por exemplo, é um processo natural, comum e até esperado. Contudo, quando a mesma discussão se encaminha para o campo da educação, ela ganha, muitas vezes outros contornos, que vão da compreensão das redes sociais digitais como puras ferramentas a serem utilizadas nos contextos educativos curriculares até 0 descrédito das suas possibilidades enquanto espaços de construções sociais efetivas, entre elas, ensinar e aprender.

Portanto, compreendermos a aprendizagem em espaços informais na internet, como as redes sociais digitais, enquanto desafio significativo para a educação no contexto da era digital, na medida em que estes ambientes agregam e combinam experiências de vida e aprendizagem social legítimas, as quais integram, nutrem e sustentam as redes de conhecimento. O YouTube, o segundo maior site de redes sociais digitais do mundo na contemporaneidade e a maior plataforma de conteúdo audiovisual aberta, apresenta-se como representação do desafio que é ensinar e aprender em contextos escolares "fechados", quando se tem todo tipo de conteúdo, saberes e conhecimentos partilhados livremente na internet, fora dos espaços formais de educação, e com mais acesso, engajamento e participação do que, muitas vezes, ações e atividades pedagógicas formais oferecidas por instituições de ensino regular. 
Moreira, J. A.; Lima Santana e Santana, C. \& González Bengoechea, A. Ensinar e aprender nas redes sociais digitais: o caso da MathGurl no YouTube

Neste sentido, este trabalho coloca o foco na análise de uma iniciativa individual, desvinculada de qualquer instituição de ensino e que usa os espaços comuns da rede para ensinar ou trocar saberes específicos na área disciplinar da matemática por meio da produção de conteúdo audiovisual livre sem intencionalidade escolar. Recorrendo a uma metodologia de cariz qualitativo este estudo procura, pois, analisar o canal MathGurl no YouTube, criado por uma jovem portuguesa, que entrevistámos, cujo canal dedicado a ensinar matemática de forma lúdica tem mais de três milhões de visualizações e é uma referência neste campo.

\section{REVOLUÇÃO YOUTUBE}

O YouTube nasceu em 2005 nos Estados Unidos pelas mãos de Steve Chen, Chad Hurley e Jawed Karim e rapidamente capturou o interesse das grandes empresas de tecnologia, sendo comprado em 2006 pela Google, quando tinha apenas 30 milhões de visitantes por mês (El País, 2006). A principal funcionalidade do YouTube, base de seu sucesso, é que permite, por um lado, que os utilizadores publiquem, partilhem, visualizem e comentem vídeos de forma livre, ilimitada e irrestrita, e por outro, que a visualização pública ou privada possa ser classificada por tema, gerando conversas entre os utilizadores através de possíveis comentários (Guzmán e Del Moral, 2014).

Desde a sua criação, o YouTube não parou de crescer e, como o resto das redes sociais, já faz parte da rotina diária das pessoas conectadas na Internet. Atualmente, a rede tem 1.900 milhões de utilizadores, sendo a segunda rede social no mundo, apenas atrás do Facebook. Em termos de conteúdos, o YouTube possui mais de um bilião de horas de vídeo vistas por dia, o que significa que todos os dias os utilizadores vêem no YouTube cerca de 115.000 anos de conteúdo audiovisual. Além disso, o YouTube pode ser desfrutado atualmente em 80 idiomas, o que significa que $95 \%$ dos usuários da Internet podem usar seu idioma para navegar na plataforma (YouTube, s.f.).

Em relação às idades, não há dados globais sobre o número de utilizadores por faixa etária, mas os dados existentes dos utilizadores do YouTube nos Estados Unidos é significativo e, provavelmente, podem ser uma referência para a restante população mundial. Segundo os dados da Statista (2018), 96\% dos utilizadores entre 18 e 24 anos acedem ao YouTube, número que permanece acima de $75 \%$ em todos os menores de 65 anos, caindo para $66 \%$ para utilizadores entre 65 e 75 anos e $51 \%$ para os maiores de 75 anos.

Da mesma forma que os utilizadores do YouTube aumentaram, também aumentaram os criadores de conteúdos que publicam seus vídeos nesta plataforma, criadores que foram batizados como "YouTubers" e que se definem como "usuários da Internet que publicam um vídeo no YouTube" (Rissoan, 2016, p. 384). Esses youtubers, recebem uma compensação financeira com base nas visualizações que os vídeos da plataforma têm e reúnem milhões de seguidores, ou assinantes, quando fazem o upload ou comentam sobre o assunto do próximo vídeo. De acordo com os dados da própria plataforma, o número de canais que recebem receitas superiores a US \$ 100.000 aumentou em mais de 50\% em relação ao ano anterior e o número de 
Moreira, J. A.; Lima Santana e Santana, C. \& González Bengoechea, A. Ensinar e aprender nas redes sociais digitais: o caso da MathGurl no YouTube

canais que tem mais de um milhão de assinantes aumentou num ano cerca de $75 \%$ em relação ao ano anterior (Youtube, s.f.). De todos esses youtubers, alguns destacam-se pelo número de seguidores como PewDiePie, que tem 95 milhões de assinantes, HolaSoyGerman, com 40 milhões de assinantes ou elrubiusOMG com 34 milhões de assinantes (Wikipedia, 2019).

Com esse alcance global e esses números, o YouTube posiciona-se como líder no entretenimento de novos utilizadores, embora seu potencial como ferramenta educacional também esteja sendo cada vez mais visto. Esta ideia é compartilhada por García e Gil (2018) que destacam que o YouTube tem uma grande capacidade educacional nas histórias dos vídeos que hospeda, dando como exemplo o canal Kurzgesagt, que apresenta conteúdo científico de forma informativa. Também Soukup (2014) destaca que, entre as apropriações que o autor detalha sobre o YouTube, aparecem a educação e a disseminação de conteúdos sobre arte e cultura, entre outros.

\subsection{Apropriações no YouTube: da produção à audiencia}

As redes sociais digitais são fundamentadas em regras de funcionamento variadas e isso implica apropriações diferenciadas, alicerçadas nas suas características específicas. O YouTube é um dos espaços online que são apropriados para a construção de redes sociais e fortalecimento de relações sociais. Da mesma forma que aconteceu com outras redes sociais digitais, o YouTube tem ocupado os espaços por meio das apropriações, convenções e usos que os sujeitos fazem e das finalidades que Ihes são atribuídas. Segundo Orihuela (2007), é preciso explorar o potencial dessas ferramentas em áreas como o jornalismo, a educação, a política e o marketing.

Ao analisar diversos canais no YouTube, é possível perceber que eles podem ser classificados quanto a alguns aspectos como tema, audiência alvo, alcance, dinâmica entre outros. A apropriação, portanto, é um elemento importante a ser definido e entendido, pois, mesmo as redes sociais digitais sendo criadas com uma intenção por seus desenvolvedores, é a partir do efetivo uso que os sujeitos se apropriam dos ambientes e lhes atribuem sentido.

Neste contexto a apropriação pode ser entendida como a criatividade adotada pelos internautas num contexto de cibercultura e que, normalmente, é muito diferente da proposta inicial dos sistemas (Zago, 2011). A ideia inicial do YouTube, por exemplo, era propor a qualquer utilizador comum produzir conteúdo audiovisual, algo como uma televisão em que o produtor do conteúdo é o próprio usuário, sendo sua principal estratégia de negócios as receitas de publicidade oriundas da atenção atraída pelo grande volume de vídeos da plataforma (Jenkins, Green e Ford, 2013, p. 80).

Embora a educação, a ciência e tecnologia, por exemplo, sejam categorias presentes no YouTube, selecionadas pelos criadores da plataforma para que os vídeos sejam identificados em suas descrições e durante o processo de buscas, a plataforma não nasceu com caráter pedagógico ou educativo, mas sim com o 
Moreira, J. A.; Lima Santana e Santana, C. \& González Bengoechea, A. Ensinar e aprender nas redes sociais digitais: o caso da MathGurl no YouTube

objetivo de entreter e estimular a produção de conteúdo em larga escala pelo cidadão comum de todas as partes do globo com acesso irrestrito, descentralizado e interativo. Porém muitos utilizadores perceberam e se apropriaram do YouTube como espaço importante para a construção da inteligência coletiva (Lèvy, 2011), ou seja, o conhecimento produzido pela humanidade e armazenado no ciberespaço, considerando que nenhum ser humano é capaz de conhecer tudo, mas toda a humanidade, coletivamente, sim.

Embora os conteúdos musicais e de humor ainda sejam os vídeos mais partilhados e acedidos no YouTube, existem, pelo menos, dezesseis categorias populares para os conteúdos armazenados na plataforma, segundo o estudo da Mediakix ${ }^{3}$. A análise e classificação proposta considera que o YouTube não transformou apenas a forma como são consumidos conteúdos audiovisuais, como também produziu géneros totalmente novos, milhares de símbolos e ícones da cultura pop e, ainda, novas profissões no século XXI.

Assim, na tipologia de classificação dos vídeos no YouTube do Mediakix (2016), interessam-nos, sobretudo duas categorías: How-Tos/Tutorials e Educacional. Os vídeos How-Tos apresentam conteúdos no estilo de tutorial, faça-você-mesmo ou aprenda-você mesmo, e é uma das três categorias com maior conteúdo e audiência do YouTube. Esses vídeos têm natureza educativa e didática, objetivando ajudar a audiência a aprender sobre uma tarefa ou tema específico, atemporalmente. Por outro lado, os vídeos educacionais, normalmente, são direcionados para uma audiência específica, segmentada por dados demográficos como faixa etária, nível de ensino que o utilizador frequenta ou área do conhecimento de interesse. Os vídeos educativos oferecem ao público informações por meio de conteúdos apresentados, normalmente, em formatos dinâmicos e divertidos.

Estas duas categorias reúnem conteúdos que mantêm a audiência informada, muitas vezes respondendo questões, analisando e resolvendo problemas simples e complexos, apresentando factos ilustrativos interessantes para a compreensão de conceitos e, portanto, são responsáveis pelo alto tráfego e exibições repetidas, podendo acumular altos números de visualizações e gerando visibilidade e popularidade para seus produtores de conteúdo. Visibilidade e popularidade são valores ambicionados pelos produtores de conteúdo do YouTube, esses tipos de capital social, alimentam a economia da plataforma, cujo padrão é gerar valor por meio da circulação do conteúdo. Ou seja, as pessoas que produzem conteúdo para o YouTube, promovendo novas apropriações da plataforma, compõem a sua engrenagem, da qual também fazem parte a audiência. Institui-se, portanto, novos modelos de produção, distribuição e consumo de informação e conhecimento, com pouca filtragem institucional ou burocracia de controle.

Os capitais sociais que circulam em redes, como o YouTube, estão intimamente relacionados à audiência que os perfis possuem na plataforma. A audiência é um

${ }^{3}$ https://mediakix.com/blog/most-popular-youtube-videos/ 
Moreira, J. A.; Lima Santana e Santana, C. \& González Bengoechea, A. Ensinar e aprender nas redes sociais digitais: o caso da MathGurl no YouTube

elemento importante nos processos comunicacionais como um todo, já que as pessoas escrevem e falam para alguém, ou seja, para uma audiência.

Segundo Alzamora (2012), audiência é uma definição dos estudos comunicacionais desde a década de quarenta, quando se investigavam os efeitos do mass media na sociedade de massa. A autora resgata os enfoques da comunicação para a percepção da audiência, procurando compreender o conceito à luz da cibercultura. Uma das perspetivas está associada aos fenómenos, dispositivos e artefactos culturais promovidos para e pela Web 2.0 e considera as diversas lógicas de comunicação que coexistem na internet, relacionando aos modelos de mediação social e, consequentemente, aos contextos múltiplos de audiência. As visualizações, likes, inscrições e comentários que elencam os vídeos mais populares no YouTube; os amigos, likes e comentários no Facebook; os seguidores, retuítes e Trend Topics no Twitter, os likes, comentários e visualizações no Instagram desenham as audiências nestas redes sociais digitais (Santana, 2014).

Embora considere elementos quantitativos, a audiência, no contexto da Web 2.0, da intermídia, está associada à produsage (Alzamora, 2012). O conceito de produsage, difundido por Bruns (2007; 2011), sustenta-se no argumento de que, dentro das comunidades que envolvem a criação colaborativa, ampliação de informações e circulação de conhecimento, os papéis distintos de consumidor e utilizador desapareceram.

Se nas mídias de massa a audiência deriva prioritariamente de estratégias mercadológicas fundadas em centros privilegiados de emissão, nas mídias sociais a audiência deriva predominantemente da diversificação das mediações sociais, do compartilhamento e da apropriação social de informações (Alzamora, 2012, p. 56). Essa dinâmica diferenciada, especialmente de convergência, implica pensar que, na seara da internet, perfis individuais, hubs ${ }^{4}$ ou pequenos grupos influenciam outros grupos e redes e até a mídia de massa, dependendo da dimensão da rede que forma em torno de cada tema. No YouTube, isso pode ser percebido no número de inscritos dos canais, nas tags utilizadas nos vídeos que indicam indexadores utilizados para classificação e busca, nos temas mais comentados, no ranking do vídeo e do canal e, consequentemente, o tamanho da rede em volta do conteúdo ou do Youtuber (Santana, 2014).

Essa engrenagem, de mão dupla, colabora para a construção de uma audiência e transmissão mais livre, autónoma e personalizada, uma vez que os atores da rede são produtores e consumidores, muitas vezes simultaneamente, mas sobretudo, porque a interação direta, de produtor e consumidor, atribui um outro sentido de dimensão cultural, diminuindo barreiras para a participação, mas também criando estímulos sociais para que as pessoas produzam e compartilhem suas produções umas com as outras, ampliando, de forma crescente, o catálogo de plataformas

\footnotetext{
${ }^{4}$ Hub é um tipo de conector nas redes sociais. É o nó que, por estar conectado a muitos nós, desempenha uma função central e de conexão para a rede. Seria um líder de opinião, capaz de influenciar outros atores, por conta do papel que desempenha na rede (Barabási, 2003).
} 
Moreira, J. A.; Lima Santana e Santana, C. \& González Bengoechea, A.

Ensinar e aprender nas redes sociais digitais: o caso da MathGurl no YouTube

como YouTube. "Essas práticas fazem de seus praticantes melhores 'leitores' de sua própria cultura e mais conscientes e críticos sobre a cultura na qual atuam e, portanto, permitem que se tornem participantes mais conscientes nos diálogos dentro dessa cultura" (Benkler, 2006, p. 15).

O facto incontestável de que o YouTube tornou-se palco para todo tipo de autoria e atividade produzidas por diferentes grupos sociais (desportistas, fãs, artistas, ativistas, professores, cientistas, militantes, praticantes de hobbies diversos, etc) levou para a plataforma as características, inovações e histórico de produção de conteúdo e mídia dos agregados dos quais os atores sociais fazem parte. Esse movimento contribui para a democratização dos canais de comunicação, mas também, para a difusão de saberes e conhecimentos específicos, singulares e personalizados. Cabe destacar, contudo, que esta dinâmica não implica superação de outros modelos de comunicação e interação. Jenkins (2006) desconstrói a retórica das especulações iniciais sobre a revolução digital, desenhando o conceito de cultura da convergência, o que significa dizer nesse contexto digital, que as mais diversas mídias e tecnologias digitais não enterraram simplesmente tudo o que é analógico. Pelo contrário, ambas convivem, dialogam e convergem em suas complexas interações e colaborações. Ainda que a discussão do autor seja no campo da comunicação, ela pode ser ampliada e transposta para a educação, onde o contexto é muito próximo, embora enfrente maior resistência quanto às mudanças dos contextos sociais.

Assim, esse grande catálogo ou acervo público de audiovisual presente em plataformas de partilha de vídeos, como o YouTube, além de convidar internautas a produzir conteúdos e partilhar em rede, em alguma medida, convoca os sujeitos que circulam na rede a consumirem os conteúdos produzidos de forma livre. Esse coletivo de pessoas que produz, difunde e consome informação e conhecimento, de forma livre e sem intermediários, parece inaugurar um novo contexto de ensinar e aprender.

\subsection{Ensinar e aprender no YouTube}

Passada a Galáxia de Gutenberg, descrita por McLuhan (1977) como regida pela cultura manuscrita, da página impressa, da cultura tipográfica na Antiguidade e Idade Média, a sociedade moderna entrou na Era Industrial conduzida pela industrialização, pelo fim da sociedade colonial, pela mecanização de produção de bens e pelo aumento do volume de produção e consumo de bens industrializados (Santana, 2006). Atualmente, a sociedade pós-industrial está imersa na Galáxia da Internet da Sociedade em Rede (Castells, 2003), baseada na revolução digital ou na quarta revolução industrial (Schwab, 2019), resultado de transformações complexas, intensas e relevantes em todos os setores da sociedade. Uma mudança de paradigma no modo como trabalhamos, nos comunicamos, nos expressamos, nos informamos, nos divertimos e aprendemos.

Os dois últimos séculos podem ser recordados pelo grande volume de investimentos públicos contínuos na educação formal, ou seja, em escolas, institutos 
Moreira, J. A.; Lima Santana e Santana, C. \& González Bengoechea, A. Ensinar e aprender nas redes sociais digitais: o caso da MathGurl no YouTube

e universidades, com o objetivo de garantir o que Hartley chama de alfabetização impressa de baixo custo (2009, p. 169). Contudo, atualmente os sujeitos que estão hoje em processo de formação, em idade regular, especialmente nas escolas e, em alguma medida, nas universidades, são aqueles que já nasceram na sociedade digital, submersos num mar de informações (Martino, 2005), interagindo, no cotidiano, inicialmente com controles remotos, joysticks e, posteriormente, com teclados, mouses, computadores, mp4, celulares, notebooks, smartphones, tablets e outras tecnologias digitais.

Filhos de uma cultura midiática e de simulações, estes sujeitos consomem seus elementos, seus produtos, mas não o fazem de maneira unilateral, mesmo porque eles também os produzem, os recriam e os manipulam. Estes jovens, a chamada screenagers (Rushkoff, 1999), nativos digitais (Prensky, 2001), geração @ (Feixa, 2006), ou encaixados em tantas outras denominações apresentadas pela comunidade académica e científica, são mais que consumidores das tecnologias digitais e informações em rede, eles as alimentam, enviam-lhes conteúdos, recriam.

Claramente, os adolescentes não veem os computadores como tecnologia. É como se tivessem desenvolvido uma habilidade inata para mensagens de texto, uso de iPods, videogames e comportamento multitarefa em plataformas múltiplas. Eles podem compartilhar as histórias de suas vidas no Facebook, divertirem-se uns aos outros no YouTube, entreter-se filosoficamente na blogosfera, contribuir com conhecimento na Wikipédia, criar arte de primeira qualidade no Flickr e compilar arquivos no del.icio.us. Alguns quase podem fazer a maioria dessas coisas ao mesmo tempo e então submeter seus resultados para uma ética online de inteligência coletiva e de melhora cíclica que, na essência, é um modo científico. Mas eles aprendem muito pouco disso na escola (...) (Hartley, 2009, p. 170).

O que Hartley (2009) destaca é que os jovens, na contemporaneidade, estão a aprender a linguagem digital, e tudo mais que decorre dela, fora da escola e de uma forma bem diferente daquela que a escola está habituada a fazer. Esses nativos digitais não apenas consomem ou aprendem, mas ensinam, também aprendendo, entre seus pares que, como eles, compreendem os códigos, linguagens e assimilam bem as noções e conceitos de tempo e espaço no contexto da revolução digital. Além disso, como também destaca o autor, os sistemas de ensino formal responderam à era digital com a proibição de acesso aos artefatos e ambientes digitais nos seus espaços institucionais, inclusive ao YouTube, com raras exceções e, nestes casos, sob forte controle e vigilância. Tudo aquilo que era informação ou conteúdo não-escolar, era tratado como entretenimento sem utilidade.

Deste modo, parece que no início desse processo de revolução digital, os jovens começaram a apropriar-se dos espaços da rede, longe das vigilâncias excessivas e limitações dos currículos pouco flexíveis das instituições formais, para desenvolver a criatividade, a produção de conteúdo dinâmico, interativo e lúdico, de maneira mais livre, a respeito daquilo que conheciam, descobriram ou estavam interessados em saber. "Portanto, enquanto as escolas e universidades se mantiveram distantes, o 
Moreira, J. A.; Lima Santana e Santana, C. \& González Bengoechea, A. Ensinar e aprender nas redes sociais digitais: o caso da MathGurl no YouTube

entretenimento inútil supriu uma demanda pela expressão pessoal, criativa e pela comunicação entre os jovens" (Hartley, 2009, p. 170).

Se antes a participação dos consumidores, no contexto digital se resumia, muitas vezes, às suas opiniões sobre o que liam ou assistiam, a revolução digital, que inicia com a Web 2.0, possibilitou a produção de conteúdo criativo, especialmente do tipo DIY ou DIWO "faça você mesmo" ou "faça com os outros", pelos próprios utilizadores de forma autónoma, sem necessidade de aprovação, filtragem ou limitação hierárquica.

Há trinta anos atrás, McLuhan (1986) já sinalizava que a maior parte do que se ensinava e aprendia acontecia fora da escola, tendo em vista a quantidade de informação divulgada pelos mídias de massa que superava a quantidade de informação comunicada pela instrução escolar, e que, naquela altura já provocava nas instituições de ensino algum desconforto em lidar com esses espaços nãoescolares. As ponderações de McLuhan antecedem a popularização da Internet e apontam para contextos de consumo de informação, de ensinar e aprender para além dos muros escolares. Essa conjuntura, potencializada pelos meios de comunicação de massa no século XX, e ampliada pelas tecnologias digitais no século XXI, reinvidicou outro olhar para as práticas pedagógicas de modo a dialogar com um mundo repleto de informações e que rapidamente se modifica, demandando novas aprendizagens, métodos, espaços e formas de ensinar e comunicar (Santana, 2019).

\section{METODOLOGIA}

Neste estudo pretendemos, fundamentalmente, e como já referido, analisar o canal de YouTube, conhecido como MathGurl, que se tem dedicado, desde a sua criação, ao ensino na área científica da Matemática. A natureza da indagação levounos a considerar pertinente um estudo qualitativo, onde o discurso direto se submete a uma lógica interpretativa, que, ao enquadrar e explicitar a posição da fundadora do canal, pretende dar conta da sua visão acerca do canal criado por si. Situando-nos, portanto, num quadro de um paradigma não positivista e interpretativo de natureza fenomenológica e ideográfica (Cohen e Manion, 1990) recorremos, nesta investigação, a uma metodologia de cariz qualitativo que põe a tónica na revalorização da "pessoa", como sujeito de conhecimento capaz de refletir, de racionalizar, de comunicar e de interagir. Com o intuito de suscitar a emergência de dados referentes ao estudo, recorremos à utilização da entrevista semidiretiva e para analisar os dados da entrevista recorremos a uma técnica de investigação capaz de codificar as declarações semi-livres e aparentemente desordenadas: a análise de conteúdo (Bardin, 1977).

\section{RESULTADOS}

Como já foi referido, este trabalho foca-se na análise do canal MathGurl, criado no YouTube em 2012, sendo que o vídeo mais antigo presente no canal foi publicado em setembro de 2015.

Revista de Comunicación de la SEECI. 15 noviembre, 2019 / 15 marzo, 2020, nº 50, 107-127 
Moreira, J. A.; Lima Santana e Santana, C. \& González Bengoechea, A. Ensinar e aprender nas redes sociais digitais: o caso da MathGurl no YouTube

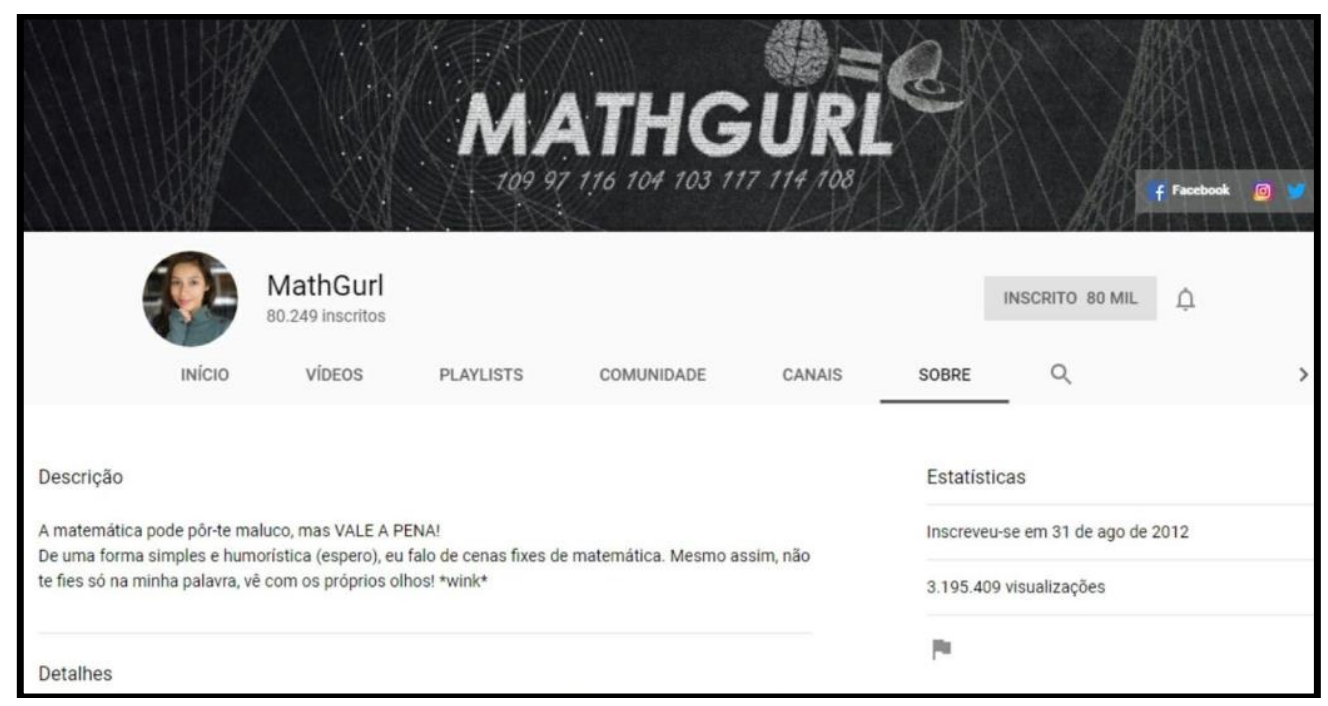

Imagem 1: Tela de descrição do canal MathGurl.

Fonte: Autores.

A autoria e produção dos conteúdos do canal é de Inês Guimarães, uma portuguesa de vinte e um anos, estudante de Matemática, autora do livro Desafios matemáticos que vão te enlouquecer, com oitenta mil duzentos e quarenta e nove (80.249) inscritos e cento e vinte, mais de três milhões e cem mil de visualizações dos cento e vinte e oito (128) vídeos publicados ${ }^{5}$. A produção dos conteúdos de matemática teve início no Facebook quando ela tinha treze anos com uma página de curiosidades e desafios matemáticos. Os conteúdos começaram a ser produzidos no Facebook em textos e imagens, até que a Inês Guimarães, que ainda não era a MathGurl, percebeu que a forma como ela gostava mais de comunicar era oralmente.

Porque me estou a expressar em forma escrita, se a maneira que gosto mais de comunicar é em vídeo? Então, eu comecei a colocar vídeos sobre curiosidades matemáticas no próprio Facebook, mas depois pensei...hum, talvez o Facebook não seja a plataforma mais adequada para vídeos, porque existe uma coisa chamada YouTube que é exclusivamente dedicada a vídeos. Então decidi criar um canal lá. Inicialmente chamei-lhe Inês Guimarães, mas tu andas pelo YouTube e vês que os canais, na maior parte dos casos, não têm os nomes das pessoas. E eu pensei que podia ter uma coisa mais alusiva à matemática. No início eu fazia vídeos em português e inglês porque pensei que, se calhar, chega a mais pessoas. Portanto, eu queria dar um nome que não fosse português, mas fosse em inglês para ser mais universal e queria que tivesse algo com math. Então, usei um gerador de nomes de utilizador no Google onde, basicamente, se colocam as palavras-chaves e ele dá sugestões. Pus a palavra math e uma das sugestões foi Math Guru. Ora, eu não sou uma guru, ainda sou um bebé na matemática, mas pensei que guru é muito parecido com girl com u...então, eu sei que girl escreve com i, mas com u fica com mais estilo, inspirado por esse tal guru. Depois vieram me dizer que gurl

${ }^{5}$ Dados retirados do canal Mathgurl no YouTube (https://www.youtube.com/channel/UC5RV s1]hiQI4HfexEIb2Q/videos) em 17 de junho de 2019. 
Moreira, J. A.; Lima Santana e Santana, C. \& González Bengoechea, A. Ensinar e aprender nas redes sociais digitais: o caso da MathGurl no YouTube

é equivalente a gaja aqui em portugal, ou seja, girl, com i, é menina e gurl, com u, é gaja, mas cool... (informação verbal ${ }^{6}$ ).

Assim, nasceu o canal MathGurl que, embora nascido em Portugal e criado por uma portuguesa, tem a sua maior audiência entre o público brasileiro. Nos primeiros anos do canal, o público brasileiro chegou a $80 \%$ da audiência, atualmente, segundo Inês, a audiência entre portugueses e brasileiros está mais equilibrada, sendo $40 \%$ de utilizadores residentes em Portugal e 60\% de utilizadores residentes no Brasil. Esse panorama pode ser compreendido a partir de alguns parâmetros, sendo um deles o conhecimento de perfil dos internautas conforme sua localização geográfica de acesso. Neste caso, os brasileiros estão em terceiro lugar entre os que mais passam tempo e interagem na internet ${ }^{7}$, o que se pode constituir como um dos fatores para o canal MathGur/ ter uma audiência tão significativa noutro país. O facto de tanto Brasil quanto Portugal serem países falantes de língua portuguesa e dos conteúdos serem produzidos no mesmo idioma, é um outro elemento a ser considerado. A youtuber @mathgurl chama atenção para uma outra ponderação diante do que conhece da sua audiência localizada no Brasil.

Eu acho que é porque os brasileiros têm muito mais a cultura de assistir a canais e vídeos educacionais, aprender por vídeos. Por aqui em Portugal meu canal é o único. Não há a cultura de aprender a ver vídeos...pois claro, também, que os brasileiros são muito mais. Os brasileiros são também mais abertos, interativos e comentam mais. $E$, claro, brasileiro puxa brasileiro...mas, se calhar, a educação pública pode estar a andar mal no Brasil, por isso os brasileiros podem ter mais a necessidade de aprender através de conteúdos online. Há pouco tempo estive a conversar com uma pessoa do YouTube do Brasil e ela disse isso mesmo: em Portugal o YouTube está atrasado uns quatro anos relativamente ao Brasil. E no Brasil há mais canais educacionais, porque as pessoas usam os vídeos como apoios online para estudar para o vestibular e para a escola (informação verbal).

O testemunho da @mathgurl indica duas variáveis importantes: a questão cultural e as lacunas da educação formal no Brasil. Em relação ao primeiro ponto cabe destacar que a cultura brasileira é diversificada e múltipla e que a Internet e a apropriação que o brasileiro faz dos seus espaços é um elemento de um panorama muito mais amplo. Assim, embora as culturas se hibridam (Canclini, 1997) e o sujeito seja fragmentado em diferentes identidades que se relacionam e coexistem (Hall, 2005) há aspectos que definem um povo. No que diz respeito à sociedade em rede, diversas pesquisas apontam, desde a popularização da internet no final da década de 90, o Brasil como grande utilizador da rede por seu perfil comunicativo, destacandose como a segunda população mais consumidora de conteúdo na Internet, ficando apenas atrás dos Estados Unidos. A outra importante variável diz respeito às fragilidades da educação no país, sobretudo na rede pública. Neste sentido, os jovens brasileiros são grandes consumidores de conteúdos online, seja pela

\footnotetext{
${ }^{6}$ Entrevista concedida por Inês Guimarães. Entrevista I. [mai. 2019]. Braga, 2019. 1 arquivo.mp3 (38 $\min$.$) .$

7 https://www.tudocelular.com/mercado/noticias/n119125/brasil-internet.html
} 
Moreira, J. A.; Lima Santana e Santana, C. \& González Bengoechea, A. Ensinar e aprender nas redes sociais digitais: o caso da MathGurl no YouTube

necessidade de complementar as lacunas da educação formal, porventura existentes, seja para interagir, movimentar as redes e, muitas vezes, serem produtores de conteúdos. Uma dinâmica diferente da sociedade portuguesa, que consome e produz menos conteúdos e em menor intensidade. Assim, embora também existam algumas fragilidades no sistema de ensino público português, parece que os sujeitos portugueses ainda não se apropriaram da rede como um espaço em que se ensina e aprende informalmente, como no Brasil.

É importante destacar a compreensão do processo de ensino-aprendizagem como um processo ligado ao desenvolvimento humano pelo qual habilidades, competências e conhecimentos são construídos a partir da assimilação de conceitos, procedimentos, valores etc., sejam por meio de vivências, experiências, observação ou interação em espaços pedagógicos formais e informais. Na perspetiva deste estudo, o processo de ensinar e aprender é sociocultural e, portanto, forjado frente aos saberes articulados oriundos da cultura e das experiências do mundo.

Assim, o mundo da vida social é a primeira instância de alicerce dos contextos de ensinar e aprender. Ou seja, a condição social de aprendiz do ser humano antecede qualquer instituição formal destinada a este fim. Ensinar e aprender, portanto, constitui-se um fenómeno situado na esfera da constituição do conhecimento, uma construção que envolve o diálogo e os conhecimentos acumulados pela humanidade. Nesta perspetiva, aprender é mais que reter, acumular, decorar dados, informações. Aprender é contextualizar e estabelecer sentido a partir do diálogo, num contexto que, antes de tudo, é sócio- histórico e faz sentido para o sujeito.

Por estas razões é que aprender não tem vínculo permanente e exclusivo com um espaço ou instituição específica. Aprender está para a escola, para os diálogos via internet, para a interação via conteúdos partilhados em redes sociais digitais e para diversas outras experiências do homem e seu ambiente social. No contexto das redes sociais digitais, percebemos que um dos elementos para a produção de conteúdos é justamente $o$ entendimento de que este precisa ser contextualizado, fazer sentido para a audiência e, de alguma forma, também para quem o produz.

No caso do conteúdo produzido para o canal MathGurl, além da preocupação com o contexto e propriedade em relação ao conteúdo, a autora procura produzir o conteúdo considerando dois outros aspectos: novas formas de apresentar conceitos de modo a não aborrecer os seguidores e utilização de uma linguagem e procedimentos que agregue e não afaste a audiência.

Em relação aos temas dos vídeos, faço muitas pesquisas na internet. Às vezes sou inspirada por coisas que aprendo nas aulas, outras vezes ouço sugestões de amigos, professores e seguidores. Acima de tudo, eu tento que sejam temas que não requiram muitos conhecimentos prévios para que toda a gente consiga aprender com algum nível de esforço...mas também tento trazer vários níveis de dificuldades: coisas mais básicas, outras avançadas...no fundo para não perder ninguém... para que aqueles que já sabem mais matemática não fiquem aborrecidos. Tento trazer sempre uma perspectiva nova, alguma forma nova e diferente de olhar para aquele assunto e, para as pessoas que 
Moreira, J. A.; Lima Santana e Santana, C. \& González Bengoechea, A. Ensinar e aprender nas redes sociais digitais: o caso da MathGurl no YouTube

não sabem muito matemática, também consigam acompanhar (informação verbal $\left.^{8}\right)$.

A preocupação da @mathgurl em permitir que qualquer assinante do canal consiga acompanhar o conteúdo que produz não significa que a autora o produz sem se preocupar com a veracidade ou legitimidade das informações. Afinal, trata-se de alguém que, além de ter afinidade com a área para a qual produz, a estuda, ou seja, atualiza-se e tem a própria comunidade como avaliadora do que partilha. Porém, há ainda que sublinhar o destaque que Inês Guimarães atribui ao tentar entender como a sua audiência gostaria de aprender sobre o conteúdo que ela produz. Isso é possível pela proximidade da autora com o universo em que está inserida, por conhecer sua audiência, a partir das ferramentas que o YouTube fornece e, portanto, colocar-se no lugar de quem procura ou acompanha os conteúdos. Esse aspecto está muito relacionado com a personalização dos ambientes de aprendizagem, um elemento importante nos contextos de ensinar e aprender na contemporaneidade. Isso permite autonomia para quem quer aprender sobre uma área, rever conteúdos que já conhece, e liberdade para construção de um itinerário de aprendizagem menos universal e mais específico.

Tento ser o mais correta possível no conteúdo que transmito, sem ter demasiado rigor para não perder as pessoas. Tento não dizer asneiras e tento sempre trazer uma perspectiva diferente sobre a matemática, algo que as pessoas não pensaram, exemplos que não foram dados, curiosidades novas (...) Eu penso: se fosse eu, qual seria a melhor maneira de transmitir isso? Penso que quem está do outro lado são pessoas como eu (informação verbal $^{9}$ ).

O uso mais democrático da internet, e a cultura oriunda dela, possibilitaram relações sociais de enorme impacto social, económico e político, a nível local e global, gerando novos espaços de poder relacionados com o conhecimento nos quais encontramos brechas para ações educativas. No caso das redes sociais digitais, as possibilidades de construções sociais, produção de saberes e trocas comunicativas através de interação síncrona e assíncrona são inúmeras. As redes que se organizam e são construídas a partir dos conteúdos partilhados nas plataformas e sites de redes sociais digitais são compostas por interlocutores virtuais com interesses que vão do conhecimento científico ao conhecimento espontâneo. Os sujeitos valem-se desses espaços para trocas intelectuais, sociais, afetivas e culturais, possibilitando o surgimento de sentimentos e estabelecendo teias de relacionamentos, mediadas pelas redes sociais digitais.

Tenho tido um feedback bastante positivo. Acima de tudo o que me motiva a fazer vídeos é esse apoio das pessoas do outro lado... eu sinto, se calhar, que posso estar fazendo alguma coisa de útil. Recebo muitas mensagens das pessoas a dizerem: eu não gostava de matemática, mas agora com seus

\footnotetext{
${ }^{8}$ Entrevista concedida por GUIMARÃES, Inês. Entrevista I. [mai. 2019]. Braga, 2019. 1 arquivo.mp3 (38 min.)

${ }^{9}$ Entrevista concedida por GUIMARÃES, Inês. Entrevista I. [mai. 2019]. Braga, 2019. 1 arquivo.mp3 (38 min.)
} 
Moreira, J. A.; Lima Santana e Santana, C. \& González Bengoechea, A. Ensinar e aprender nas redes sociais digitais: o caso da MathGurl no YouTube

vídeos, percebi que era uma área diferente; os teus videos me motivam a estudar matemática; tive $100 \%$ no último teste porque agora gosto de matemática. Claro que alguns desses comentários são só simpatias exageradas, porque não é a ver um vídeo que, de repente, uma pessoa passa a saber matemática. Mas meu objetivo é mesmo mais a parte da motivação e mostrar que a matemática pode ser encarada de uma forma diferente e divertida. Fico muito mais contente que as pessoas dizem tão bem e apreciam o que faço e parecem ganhar alguma coisa com isso (informação verbal ${ }^{10}$ ).

Percebemos pela fala da @mathgurl que, embora ela produza conteúdo relacionado com uma área de conhecimento que tem uma vasta produção científica e académica, a sua audiência sinaliza que, a partir do conteúdo produzido por ela, os sujeitos ficam motivados a conhecer e, muitas vezes, desconstruir a tensão que está à volta de uma área que, na escola, é trabalhada muitas vezes de forma descontextualizada, afastando os estudantes, mais do que os aproximando. Assim, motivação e ludicidade são dois eixos importantes na produção dos conteúdos da estudante para o seu canal. É a produção de alguém que aprendeu matemática de forma tradicional e percebe que esse modelo distancia o estudante de uma área que é fundamental para o desenvolvimento humano.

A percepção e propósito da @mathgurl ao desenvolver um canal no YouTube, passa primeiro pelo desejo de partilhar o que sabe de uma forma que motive as pessoas, sabendo, contudo, que esse espaço construído por ela não substitui o espaço formal escolar, mas pode-se constituir como complemento ou mesmo gatilho para que os sujeitos se mobilizem a conhecer, saber, ou mesmo se divertir, com a matemática.

Vale destacar que embora o canal MathGurl se considere um canal de entretenimento, ele está categorizado no YouTube como ciência e tecnologia e ao analisar os conteúdos postados por sua idealizadora, podemos perceber que os vídeos produzidos tratam de conceitos, procedimentos e noções da mesma matemática que é discutida nos espaços formais, contudo, com uma linguagem próxima ao cotidiano, exemplos práticos e dinâmica lúdica, que busca entreter e garantir a atenção da audiência para a compreensão de teorias, teoremas e conceitos muitas vezes complexos.

${ }^{10}$ Entrevista concedida por GUIMARÃES, Inês. Entrevista II. [mai. 2019]. Braga, 2019. 1 arquivo.mp3 (30 min.) 
Moreira, J. A.; Lima Santana e Santana, C. \& González Bengoechea, A. Ensinar e aprender nas redes sociais digitais: o caso da MathGurl no YouTube

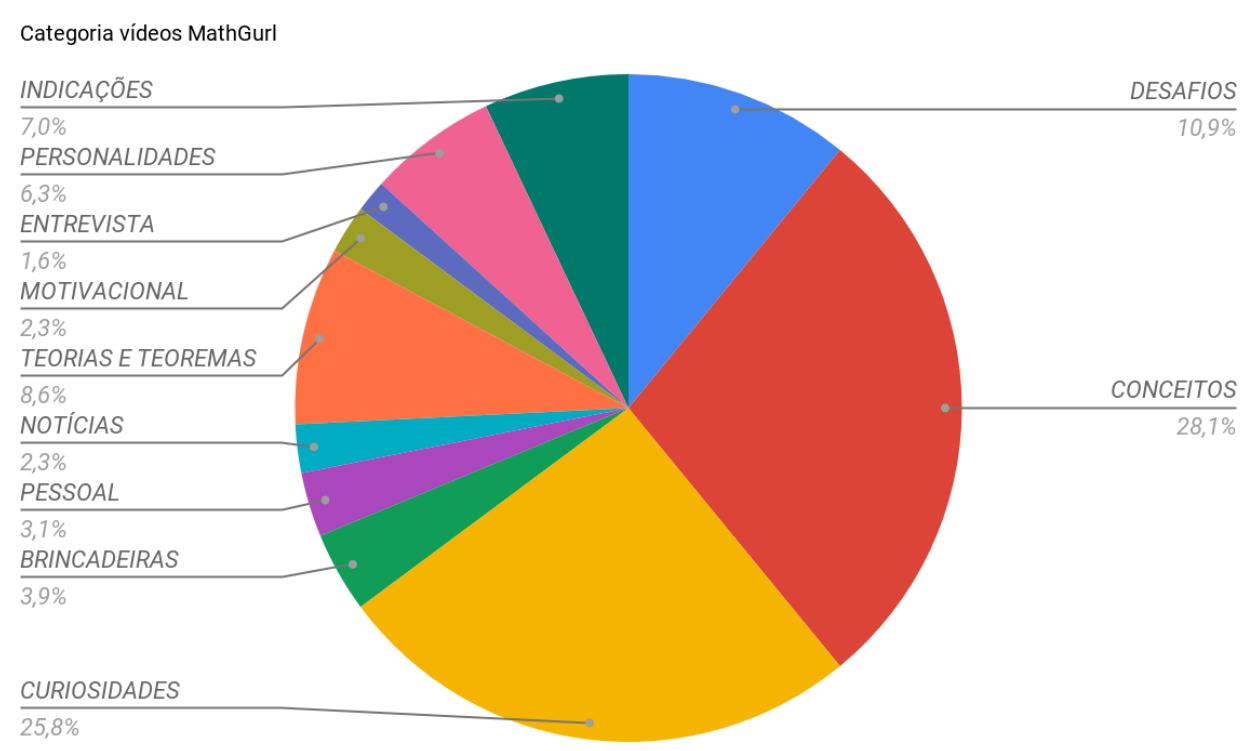

Gráfico 2: Categorização dos vídeos da MathGurl no YouTube Fonte: Autores.

Considerando o gráfico acima mais de $50 \%$ do conteúdo produzido é difusão de saberes matemáticos na dimensão do esclarecimento de conceitos matemáticos, curiosidades matemáticas e desafios matemáticos sempre amparada na literatura da área do conhecimento, com exemplos claros e linguagem dinâmica e divertida. Cabe destacar ainda que, embora a autora se preocupe com as referências que apresenta, com o rigor dos dados apresentados, ela também adequa o conteúdo produzido à dinâmica dos utilizadores que acedem a esse tipo de produto. Assim, os vídeos são curtos, com menos de dez minutos de duração; possuem uma identidade, a mesma saudação e despedida com a audiência; dialoga com outros elementos mediáticos, especialmente recursos e associações com a cultura pop; fazem referência a outros vídeos produzidos pela autora, inclusive, algumas vezes, propondo continuidade; e utiliza linguagem que busca aproximar a audiência de quem produz o conteúdo, especialmente convidando à interação e/ou respondendo os comentários enviados para cada conteúdo.

Há que se destacar ainda que, em muitos vídeos, a MathGurl ressalta a importância de aprender nas mais diversas formas, reforçando a importância de professores e instituições como espaços que são legitimamente responsáveis por esse processo e, portanto, precisam ser respeitados e valorizados.

"Embora seja um bocado utópico, eu acho que as pessoas deviam gostar de aprender porque saber coisas é a melhor coisa que a gente pode fazer. Eu valorizo imenso o conhecimento e preciso estar sempre a aprender coisas novas" (informação verbal $\left.^{11}\right)$.

${ }^{11}$ Entrevista concedida por GUIMARÃES, Inês. Entrevista II. [mai. 2019]. Braga, 2019. 1 arquivo.mp3 (30 min.) 
Moreira, J. A.; Lima Santana e Santana, C. \& González Bengoechea, A. Ensinar e aprender nas redes sociais digitais: o caso da MathGurl no YouTube

Ainda que a MathGurl reforce nos vídeos que não é professora, mesmo algumas pessoas tendo a recomendado para o prémio de melhor professora de Portugal, por exemplo, e tenha destacado na entrevista realizada que não pretende ser docente, não se pode negar que o conteúdo gerado por ela de difusão de saberes e divulgação científica da matemática está na dimensão de ensinar livremente e em rede, nos contornos das pedagogias das conexões. As pedagogias das conexões, instituídas no âmbito da revolução digital favorecem acesso livre a conteúdos e saberes partilhados das mais diversas formas na rede, promovendo aprendizagens ubíquas no ciberespaço, forjando novos papéis profissionais e espaços de aprendizagem. Essa dinâmica de ensinar e aprender informalmente, especialmente nas redes sociais digitais, muitas vezes tem início e fim nela mesma, tendo impacto direto na educação formal que são faces do mesmo objeto que é a educação (Santana, 2019).

No caso do YouTube, os vídeos produzidos diretamente para a plataforma, tem por finalidade a difusão de informação e conhecimento no ciberespaço, retratando sua proposta essencial e original: "Broadcast yourself" ou "transmita você mesmo". São conteúdos produzidos de forma independente, por pessoas comuns, que querem, basicamente, produzir conteúdos em vídeos e partilhá-los. Assim, o que há de revolucionário no YouTube no contexto do que temos nomeado como pedagogias das conexões é que ele representa, uma apropriação comum do discurso (Jenkins, 2009), onde tanto a mídia de massa é utilizada e recombinada, ao tempo que a mídia amadora ganha acesso público em grande escala. Na dimensão do ensinar e aprender o contexto é similar, ao tempo que os pressupostos académicos, científicos e pedagógicos são evocados, as práticas pedagógicas não formais ganham espaço, visibilidade e constroem redes que ensinam e aprendem.

\section{CONCLUSSÕES}

Recentemente têm surgido muitos trabalhos que procuram identificar e explorar o potencial educativo de redes sociais digitais, como o MySpace, Orkut, Ning, Facebook e sobretudo o YouTube, que referem, por exemplo, que esta rede pode potenciar a comunicação e a partilha de informação e conhecimento, e pode permitir o desenvolvimento de capacidades e estratégias de ensino e aprendizagem mais dinâmicas e interativas, abertas e criativas, possibilitando uma maior participação dos intervenientes, um melhor aproveitamento dos recursos e mais mobilidade de informação e conhecimento.

Assim, e perante esta realidade, parece-nos que faz cada vez menos sentido manter modelos de organização curricular "pré-digitais" centrados numa organização rigidamente hierárquica de conteúdos estáticos sob o controlo do professor.

O nosso estudo confirma esta ideia destacando a necessidade de criar modelos e espaços pedagógicos alternativos com uma forte componente motivacional e lúdica. No entanto, e como se pode concluir, estes espaços não devem ser vistos como substitutos do espaço formal escolar, mas sim como espaços complementares onde os sujeitos se mobilizam para adquirir novos conhecimentos e se divertem com a 
Moreira, J. A.; Lima Santana e Santana, C. \& González Bengoechea, A. Ensinar e aprender nas redes sociais digitais: o caso da MathGurl no YouTube

aprendizagem da matemática. Reforçando esta ideia, em muitos dos seus vídeos, a MathGurl sublinha a importância de aprender com os professores e com as instituições educativas, já que estes são formalmente responsáveis pelo processo educativo e, portanto, precisam ser respeitados e valorizados.

Concluímos ainda que, embora a MathGurl considere o seu canal como um espaço de entretenimento, os vídeos produzidos, de curta duração, com menos de dez minutos cada, e com uma identidade própria, tratam de conceitos, procedimentos e noções da mesma matemática que é discutida nos espaços formais, mas com uma linguagem menos formal, que busca entreter e garantir a atenção da audiência para a compreensão de teorias, teoremas e conceitos muitas vezes complexos. Com efeito, este é um espaço com características próprias que nos remete para uma educação digital, aberta e em rede não formal, na proximidade de uma pedagogia conectiva, com acesso livre a conteúdos e saberes partilhados em rede, promovendo aprendizagens ubíquas no ciberespaço.

Tratando-se do uso das possibilidades das redes sociais digitais, é certo que qualquer conclusão que se tire, tem de ser considerada transitória e momentânea, pois as frequentes evoluções destes espaços geram mudanças muito rápidas. No entanto, e apesar deste fluxo constante nos impelir para a relatividade dessas conclusões, os resultados deste estudo permitem-nos afirmar que a criação destes espaços não formais de aprendizagem na rede do YouTube configuram-se como ambientes com potencial técnico e funcional que favorecem as conexões entre os participantes na rede e aprendizagens interativas; que possibilitam que os conteúdos sejam organizados em nós da rede para acesso rápido; e que facilitam a partilha de materiais, de conhecimento e de experiências de aprendizagem colaborativa e participativa (Allegreti et al., 2012; Basso et al., 2013).

\section{REFERENCIAS}

Allegretti, S., Hessel, A., Hardagh, C. \& Silva, J. (2012). Aprendizagem nas redes sociais virtuais: o potencial da conectividade em dois cenários. Revista Contemporaneidade, Educação e Tecnologia, (2), 54-60.

Bardin, L. (1977). L 'analyse de contenu. Paris: PUF.

Basso, M.; Bona, A.; Pescador, C.; Koelher, C. e Fagundes, L. (2013). Redes sociais: espaço de aprendizagem digital cooperativo. Conjectura: Filosofia e Educação, (18), 135-149.

Castells, M. (2003). The Network Society: From Knowledge to Policy. Em M. Castells \& G. Cardoso (Eds.). The Network Society, From Knowledge to Policy (pp. 3-21). Washington DC: Johns Hopkins Center for Transatlantic Relations.

Cohen, L. e Manion, L. (1990). Métodos de Investigation Educativa. Madrid: La Muralla. 
Moreira, J. A.; Lima Santana e Santana, C. \& González Bengoechea, A. Ensinar e aprender nas redes sociais digitais: o caso da MathGurl no YouTube

Davis, M. (1997). Garage Cinema and The Future of Media Thecnology. Em Communications of The ACM (50th Anniversary Edition Invited Article, 2, (pp. 4284). Disponível em: https://marcdavis.me/wpcontent/uploads/Publications/1997 CommunicationsACM GarageCinemaFutureMe diaTechnology.pdf

Díaz, A. (2015). ¿Hacemos un uso inteligente de las redes? Em J. Criado e F. Rojas. Casos de éxito en redes sociales digitales de las administraciones públicas. (pp. 8-10). Barcelona: Escola d'Administració Pública de Catalunya. doi: http://dx.doi.org/10.2436/10.8030.05.6

El País (2006). Google compra la web YouTube por 1.300 millones. Disponível em: https://elpais.com/tecnologia/2006/10/10/actualidad/1160468878 850215.html

García, F. e Gil, F. Youtubers (2018). Mundos éticos posibles. Index.comunicación, 2, 151-188.

Guimarães, I. (2019). Entrevista I. Entrevistador: Camila Lima Santana e Santana. [1 arquivo.mp3]. Braga.

Guzmán, A. e Del Moral, M. (2014). Tendencias de uso de YouTube: optimizando la comunicación estratégica de las universidades iberoamericanas. Observatório Jornal, (1), 69-94.

Prensky, M. (2001). Digital Natives, Digital Immigrants. On the Horizon, (5), 1-6.

Rissoain, R. (2016). Redes sociales. Comprender y dominar estas nuevas herramientas de comunicación. Barcelona: ENI.

Soukup, A. (2014). Looking at, with, and through YouTube. Communications Research Trends, 33(3), 3-34.

Statista. (2018). Percentage of U.S. internet users who use YouTube as of January 2018, by age group. Disponível em:

https://www.statista.com/statistics/296227/us-youtube-reach-age-gender/

Wikipedia. (2019). Anexo: Canales de YouTube con más suscripciones, Disponível em:

https://es.wikipedia.org/wiki/Anexo:Canales de YouTube con m\%C3\%A1s suscr ipciones

YouTube. YouTube para la prensa. Disponível em: https://www.youtube.com/intl/es419/yt/about/press/ 
Moreira, J. A.; Lima Santana e Santana, C. \& González Bengoechea, A. Ensinar e aprender nas redes sociais digitais: o caso da MathGurl no YouTube

\section{AUTORES:}

\section{José António Moreira}

Doutor e Mestre em Ciências da Educação pela Universidade de Coimbra. Realizou um Pós-Doutoramento em Tecnologias Educacionais e da Comunicação também pela Universidade de Coimbra. Licenciatura em História da Arte pela Faculdade de Letras da Universidade de Coimbra. É Professor no Departamento de Educação e Ensino a Distância (DEED) da Universidade Aberta. Atualmente é Diretor da Delegação Regional do Porto da Universidade Aberta e Coordenador da Unidade de Desenvolvimento dos Centros Locais de Aprendizagem da mesma universidade. É Coordenador Científico da Unidade Móvel de Investigação em Estudos do Local e investigador no Centro de Estudos Interdisciplinares do Século XX da Universidade de Coimbra e no Laboratório de Educação a Distância e eLearning (LE@d) da UAb. É ainda Coordenador do Núcleo de Estudos de Pedagogia no Ensino Superior (NEPES) sedeado no CEIS20. Tem publicado artigos científicos em revistas especializadas e livros nas áreas da Formação de Professores e das Tecnologias Digitais.

jmoreira@uab.pt

Orcid ID: https://orcid.org/0000-0003-0147-0592

ResearchGate: https://www.researchgate.net/profile/] Antonio Moreira

\section{Camila Lima Santana e Santana}

Doutora em Educação pela Universidade Federal da Bahia, Mestre em Educação e Contemporaneidade pela Universidade do Estado da Bahia e Pedagoga, graduada pela Universidade do Estado da Bahia. É pesquisadora e docente do Instituto Federal de Educação, Ciência e Tecnologia Baiano, no curso de Licenciatura em Química e no Programa de Pós-graduação em Educação Profissional e Tecnológica. Membro dos grupos de pesquisa Comunidades Virtuais (UNEB); Educação, Redes Sociotécnicas e Culturas digitais (UFBA); e Educação Científica (IF Baiano). Atualmente, está desenvolvendo estágio pós-doutoral na Universidade de Coimbra, investigando a interface da educação e redes sociais digitais no contexto da cultura digital. camilalimasantana@gmail.com

Orcid ID: https://orcid.org/0000-0002-5696-7443

ResearchGate: https://www.researchgate.net/profile/Camila Santana5

\section{Aitor González Bengoechea}

Doutorando em Comunicação Audiovisual, Publicidade e Relações Públicas pela Universidade Complutense de Madrid. Formado em Jornalismo pela Universitat Jaume I de Castellón. Possui Mestrado em Comunicação de Organizações da Universidade Complutense de Madrid. Publicou trabalhos relacionados com a dinâmica das redes sociais na comunicação e outros campos relacionados. aitogonz@ucm.es

Orcid ID: https://orcid.org/0000-0002-1509-8106

ResearchGate: https://www.researchgate.net/profile/Aitor Gonzalez Bengoechea 